\begin{tabular}{|l|l|l||}
\hline \multicolumn{2}{|c|}{ PublisherInfo } \\
\hline \hline PublisherName & $:$ & BioMed Central \\
\hline \hline PublisherLocation & $:$ & London \\
\hline \hline PublisherImprintName & $:$ & BioMed Central \\
\hline \hline
\end{tabular}

\title{
Diabetes and insulin use on AMI survival - is enough being done?
}

\begin{tabular}{|c|c|c|c|}
\hline \multicolumn{4}{|c|}{ ArticleInfo } \\
\hline ArticleID & : & 34 & \\
\hline ArticleDOI & : & $10.1186 / \mathrm{cvm}-20 \mathrm{C}$ & 72101 \\
\hline ArticleCitationID & : & 72101 & \\
\hline ArticleSequenceNumber & : & 13 & \\
\hline ArticleCategory & : & Paper Report & \\
\hline ArticleFirstPage & : & 1 & \\
\hline ArticleLastPage & : & 3 & \\
\hline ArticleHistory & : & $\begin{array}{l}\text { RegistrationDat } \\
\text { Received } \\
\text { OnlineDate }\end{array}$ & $\begin{array}{ll}: & 2001-10-18 \\
: & 2001-3-7 \\
: & 2001-10-18\end{array}$ \\
\hline ArticleCopyright & : & Biomed Central I & 2001 \\
\hline
\end{tabular}




\begin{tabular}{|l|l|l|}
\hline ArticleGrants & $:$ & \\
\hline \hline ArticleContext & $:$ & 1306322 \\
\hline
\end{tabular}

Joanna Lyford, Affl

Corresponding Affiliation: Aff1

Aff1 MedWire, UK

Keywords

Acute myocardial infarction, diabetes, insulin, mortality

\section{Context}

Diabetes is highly prevalent among elderly patients with acute myocardial infarction (AMI). This study investigates the role of diabetes in the mortality of patients with AMI.

\section{Significant findings}

The mean age of the groups lay between 75 and 78 years. Patients with diabetes had higher incidences of hypertension and prior AMI, congestive heart failure, and revascularization, especially those on insulin. Diabetics were less likely to receive aspirin, ? blockers, or undergo coronary revascularization; again, this was especially the case for those on insulin. Non-diabetic patients had the lowest mortality at both 30 days $(20.3 \%)$ and one year (33.8\%). Diet-controlled diabetic patients had the highest mortality at 30 days (24.3\%), but insulin-treated patients had the highest mortality at one year (43.5\%). Diabetic patients treated with an oral hypoglycemic agent had lower 30-day and 1-year mortality than diabetic patients treated with diet alone or with insulin.

\section{Comments}

The authors comment: "Our data suggest the mortality for elderly diabetics with acute AMI is as high as that seen in the preperfusion era and lend further credence to the notion that underutilization of 
specific therapies may contribute to this increased hazard." While conceding that there were several limitations to the study, the researchers conclude: "Our data suggest that recommended therapeutic interventions may have a significant benefit in diabetic patients and the failure to treat patients with diabetes may have an adverse impact on mortality."

\section{Methods}

Data from a retrospective cohort study of patients hospitalized with AMI were used to evaluate the role of diabetes in 30-day and 1-year mortality. Patients were classified as non-diabetics $(80,832$ patients), diet-controlled diabetics (9862), diabetics receiving an oral hypoglycemic agent $(14,664)$, and diabetics on insulin therapy at time of admission $(12,241)$.

\section{Additional information}

\section{References}

1. Berger AK, Breall JA, Gersh BJ, Johnson AE, Oetgen WJ, Marciniak TA, Schulman KA: Effect of diabetes mellitus and insulin use on survival after acute myocardial infarction in the elderly (The Cooperative Cardiovascular Project). Am J Cardiol. 2001, 87: 272-277. 